\title{
Exploitation, Vulnerability, and Social Domination
}

And because man is a human being

he doesn't care for a boot in the face.

He wants no slaves below him

and no masters above him.

\author{
Bertolt Brecht \\ "Song of the United Front"
}

This article attempts to revive a research program by criticizing it. Its object of criticism is the powerful research agenda of analytical Marxism. I shall attempt this revival by criticizing the views of two of the most influential members of that research program, G. A. Cohen and John Roemer. I will argue that they are mistaken in their identification of exploitation with exchange against the background of injustice in the distribution of assets. Exploitation should be conceived, instead, as a form of domination, that is, domination for self-enrichment. The latter conception captures intuitions surplus to the traditional analytical Marxist view, provides a richer and more plausible understanding of socialist goals, is more amenable to integration into a rigorous Marxist social science, and brings Marxism closer to radical democracy. If I am right, then the idea of exploitation will have received a new lease on life, and the Marxist armory will have been enriched by renewed focus on vulnerability and domination.

The article is structured as follows. Section I offers a general definition of exploitation as the self-enriching instrumentalization of

Thanks to Dan Halliday, Faik Kurtulmus, Roberto Veneziani, and two anonymous referees for excellent criticisms of earlier drafts of this article; John Filling and Allen Wood for helpful discussion; and audiences at Bristol, Cambridge, Leuven, Manchester, and the Nordic Network for Political Ethics Conference at Vejle for comments and suggestions.

(C) 2013 Wiley Periodicals, Inc. Philosophy \& Public Affairs 41, no. 2 
another's vulnerability. Section II restricts the purview of this definition to the economic structure of society. Section III defines domination and argues that exploitation, as conceived antecedently, is a form of domination. Section IV discusses the connection between exploitation and class domination. Section V sketches the Cohen/Roemer distributiveinjustice conception of exploitation. Section VI argues that exploitation as domination for self-enrichment supplies a better account than exploitation as distributive injustice. Section VII responds to an objection raised by Roemer against the domination-based account. Section VIII concludes.

The general definition of exploitation I propose is as follows:

(1) A exploits B if and only if A and B are embedded in a systematic relationship in which (a) A instrumentalizes (b) B's vulnerability (c) to extract a net benefit from B.

A and B are free variables referring, throughout this article, to agents or groups or coalitions of optimizing agents. The rest of this section clarifies elements (a)-(c).

A

Element (a): Exploiting is commonly and rightly associated with using. It is, moreover, a special kind of using, for it has the ring of inappropriately "playing on" (in Feinberg's apt expression) ${ }^{1}$ some set of attributes or features $S$ of another agent. Instrumentalization of $S$ implies that $S$ is being used as a means. It is, however, only when $S$ comes to cover a range of sufficiently salient attributes (in virtue of which the agent is who he is or does what he does) that we can appropriately talk about exploitation of person by person. (Exploiting someone's dribbling weakness in football need not amount to exploiting him.) According to Robert Goodin, such "whole person exploitation" obtains just when the exploitee's attributes are used unfairly: "taking advantage of other people's honesty or blindness to steal from them constitutes exploiting those people tout 
court." ${ }^{2}$ As will become clearer, I do not think unfairness is a necessary condition for whole-person exploitation (henceforth: exploitation). ${ }^{3}$ Nor is it necessary that exploitation be intentional: one can unintentionally, or unknowingly, instrumentalize another's vulnerability, and thereby exploit him. ${ }^{4}$

\section{$B$}

Element (b): Vulnerability comes in two broad forms: absolute and relational. Unlike absolute vulnerability, relational vulnerability is semantically close to dependence, but covers a broader class of phenomena. I shall unpack this distinction presently. An agent suffers absolute vulnerability just when he suffers a substantial risk of a significant loss in the relevant metric (welfare, resources, capabilities, and so on). The absence of absolute vulnerability is guaranteed by security, which implies such losses will not occur. Now, absolute vulnerability does not make essential reference to an agent's power over another, or indeed to other agents whatsoever. Periodic volcanic explosions make villagers situated near the volcano absolutely vulnerable, but human agency need not intrude on the side of the content of their vulnerability. Relational vulnerability, on the other hand, makes essential reference to other agents. B is relationally vulnerable to A only when A has some sort of power over B.

Consider the following structural analogy:

Deep Pit: People are stuck in a deep pit, each situated deeper than the other. Every now and then there are mudslides. The deeper one is, the worse he is liable to suffering from mudslides.

2. Robert Goodin, "Exploiting a Person and Exploiting a Situation," in Modern Theories of Exploitation, ed. Andrew Reeve (Thousand Oaks, Calif.: Sage, 1987), p. 171.

3. I am here in agreement with Allen Wood's nuanced discussion of Doyle Lonnegan in Allen Wood, "Exploitation," Social Philosophy and Policy 12 (1995): 136-58, at p. 152.

4. Say B is a poor man whose only valuable possession is an expensive coat. He needs to sell it in order to get food. Mistaking B for an eccentric millionaire, A offers B a very low price for the coat. B accepts because of the urgency of his need. Here A has unknowingly instrumentalized B's vulnerability and extracted a net benefit from him (the value of the coat minus the price A has paid), thereby unknowingly and unintentionally exploiting B. Assume, further, that B (falsely) believes A to be more needy than himself, and accepts A's offer for that reason. Here, it would not be irrational for both A and B to believe that B exploits A, although both beliefs are false. 
In Deep Pit the relative position of each person gives us some information as to who is more vulnerable, in the sense that, if $\mathrm{A}$ is situated higher up the pit than $B$, then we are justified in inferring either that he is not vulnerable at all or that he is less vulnerable than $\mathrm{B}$. But it is not in virtue of B's position relative to A that B is vulnerable. Rather, B is vulnerable just because $B$ is deep inside the pit and there are mudslides: B's predicament can be fully described without reference to (the positions of) any other agents. B is vulnerable in the absolute sense.

Now add the following modification to Deep Pit: A has a rope, and it would be very easy for B to use that rope to climb up, thus avoiding worse mudslides. In this case, B's vulnerability proper is no longer just a function of depth and other agent-independent facts about the world. Indeed, if we assume that it is neither difficult nor costly for B to move upward once A throws him the rope, and for A to do so, B's vulnerability becomes a function of A's willingness to throw the rope. B's vulnerability can only be described with reference to other agents, or, more precisely, the powers such agents have over B (and their dispositions to use them). ${ }^{5}$ $B$ is vulnerable in the relational sense.

Thus, one set of sufficient conditions for B being relationally vulnerable to $\mathrm{A}$ is: (i) $\mathrm{B}$ lacks some desideratum $\mathrm{x}$ that is a requirement for, or a constitutive feature of, B's flourishing ${ }^{6}$ (in which case $x$ is the object of B's need), ${ }^{7}$ (ii) B can only obtain $\mathrm{x}$ from $\mathrm{A}$, and (iii) A has it within his discretion to withhold $\mathrm{x}$ from $\mathrm{B}$. The account developed here is similar to that

5. It is true quite generally that, if A can prevent sufficiently significant losses to which $\mathrm{B}$ is liable, $\mathrm{B}$ does what he needs to do to avoid such losses, and what he needs to do is what A tells him to do, then A has power over B. This result carries over naturally to the specifically economic case, which I discuss in Section II.

6. Of course, not all failures to flourish result from relational vulnerability. That is, I do not deny that forms of absolute vulnerability (say, due to incurable and unimprovable disease) exist. All I claim is that a large number, perhaps the majority, of affronts to human dignity or frustrations to human flourishing imply or result from relational vulnerability. (A walking disability, it is often said, is no handicap for the disabled if buildings are equipped with ramps, elevators, and so on. All such disabilities constitute forms of relational vulnerability.) Exploitation is responsible for a subset of such frustrations and affronts.

7. Note that "need" here does not necessarily denote some sufficiency or decency threshold. If basic need is defined in terms of such a threshold, and human flourishing requires more than meeting that threshold, then flourishing requires the satisfaction of nonbasic forms of need. 
of Goodin, ${ }^{8}$ who has argued that states of vulnerability become morally salient when they generate exploitability, and exploitability obtains if and only if (i)-(iii) are met. ${ }^{9}$

C

Element (c): A benefits just when there is an increase in A's well-being. A obtains a net benefit when A's overall well-being increases.

Before going on to study the conceptual connection between exploitation and domination, I must narrow the scope of definition (1) to economic exploitation. Let me explain why. Exploitation, in general, has something to do with the beneficial instrumentalization of another's vulnerability. It follows that exploitation can only be completely removed either by eradicating all human vulnerability (leading to benefit) or by getting people never to engage in such instrumentalization. But the introduction of such remedies is generally either impossible or positively undesirable. Gullibility or plain ignorance constitutes (noneconomic) forms of vulnerability that render one exploitable. It is, however, usually impossible to have such traits removed or to prevent their instrumentalization. The disposition to act in good faith toward others, to take another example, can constitute vulnerability in some contexts. It is positively undesirable that such a general disposition be removed or even discouraged. Indeed, it is plausible to think that certain (noneconomic) forms of vulnerability, which tend to be reciprocal over the course of a life, are constitutive of intrinsically good relationships (for example, relationships of affection and love). ${ }^{10}$ Economic vulnerability, by contrast, is never constitutive of such relationships and is never reciprocal (see below). It pertains centrally, moreover, to the basic structure of

8. Robert Goodin, Protecting the Vulnerable (Chicago: University of Chicago Press, 1986).

9. Unlike Goodin, I do not think (iii) is a necessary condition for exploitation, for there is nothing contradictory in the thought that $\mathrm{A}$ is forced to exploit $\mathrm{B}$, and therefore lacks the said discretion. I do not need to press such disagreements here, however.

10. See Goodin, Protecting the Vulnerable, p. 193. 
society, that is, its fundamental, publicly observable, institutional features, sometimes said to form the "primary subject" of justice. ${ }^{11}$

Now, economic vulnerability can be defined as follows:

(2) B is economically vulnerable to $A$ if and only if $B$ is vulnerable in virtue of B's position relative to A in the relations of production.

The relations of production are systematic relations of effective ownership, and therefore of power, over human labor power and means of production in society. ${ }^{12}$ Say A owns a water-producing well. If A's ownership is fully enforced, B needs water, and B has no independent access to water, then B is economically vulnerable to A. The related Marxist claim is that, under capitalism, B is vulnerable to A in virtue of A's ownership of means of production and B's lack thereof, which gives A power over $\mathrm{B}$, whether or not $\mathrm{B}$ is exactly forced by his economic circumstances to supply his labor power to $\mathrm{A} .{ }^{13}$ But what does it mean for some agent to have economic power over another?

Philosophers sometimes say that A has power over B only if A can get B to $\varphi$, and B would not otherwise have $\varphi$-ed. ${ }^{14}$ This is too strong. For A can power-over $B^{15}$ even if $B$ does what he would have done anyway. What we must say, instead, is that A power-overs B if and only if $A$ is able to get B to $\varphi$ for reason S and B would not have $\varphi$-ed for S if A had not done (or failed to do) whatever he did (or failed to do) that bears on B's decision to $\varphi .^{16}$ All this hardly furnishes a sufficient condition for economic power-over, however. Economic power-over obtains just when A has the relevant ability ${ }^{17}$ (to get B to $\varphi \ldots$. ) in virtue of control over a

11. John Rawls, A Theory of Justice (Cambridge, Mass.: Harvard University Press, 1971).

12. For discussion of the distinction between formal and effective power, see G. A. Cohen, Karl Marx's Theory of History: A Defence (Princeton, N.J.: Princeton University Press, 1978), chap. 3. Broadly construed, the set of relata in the relations of production will include raw materials and machinery, as well as knowledge and perhaps human talents.

13. I discuss force in Section $\mathrm{V}$ below.

14. See, e.g., Frank Lovett, A General Theory of Domination and Justice (Oxford: Oxford University Press, 2010), chap. 3.

15. "Power-overing" (a wordplay on "overpowering") is a convenient verbalization of "power over," which I use to refer to instances of the latter type.

16. For a similar definition, see A. J. Julius, "The Possibility of Exchange," <www .ajjulius.net>. Note that the inference from "A has the ability to get B to $\varphi$ " to "B has the ability to get A to get B to $\varphi$ " is invalid.

17. Strictly: A has the relevant ableness, that is, the ability and the opportunity to do so. Ability-sentences, unlike ableness-sentences, imply counterfactual conditionals. For discussion, see Peter Morriss, Power (Manchester: Manchester University Press, 2002). 
greater share of resources than B. That is, if $W_{a}$ is A's wealth, $W_{b}$ is B's wealth, and $P a b$ stands for "A has economic power over B," then, $\forall \mathrm{a}, \mathrm{b}$ $\left(\mathrm{Pab} \rightarrow \mathrm{W}_{\mathrm{a}}>\mathrm{W}_{\mathrm{b}}\right)$.

Given this set of definitions, we can begin to construct a power-based account of economic exploitation:

(3) If A instrumentalizes B's economic vulnerability to A, then in so doing, A takes advantage of his power over B.

Here is some intuitive support for (3). In the rope variation to Deep Pit (see Section I), relational vulnerability only figures in virtue of the relative position of agents: $\mathrm{B}$ is relationally vulnerable just because some agent A somehow stands above B and can throw him the rope. This is exactly analogous to superior position in terms of wealth. ${ }^{18}$ Thus, economic vulnerability is a form of relational vulnerability, such that, if $\mathrm{B}$ does not own any means of production (or, more broadly, wealth) and A does, or B owns substantially less than A, then B is economically vulnerable to $\mathrm{A}$ and $\mathrm{A}$ has economic power over $\mathrm{B} .{ }^{19}$ In the case that exercises Marxists: assuming an equal distribution of internal resources, ${ }^{20}$ the wealth owned by capitalists systematically gives them a decisive bargaining advantage over workers, which means capitalists always have and can take advantage of economic power over workers (and never vice versa). Under capitalism, improvements in the productive power of workers, or even in their material well-being, systematically rivet them to the capitalist juggernaut "more firmly than the wedges of Hephaestus held Prometheus to the rock." ${ }^{21}$

18. It follows that there can be no "reciprocal" economic power-over: if Bill Gates and Warren Buffett own approximately the same amount of wealth, then neither power-overs the other economically. I do not deny that Gates can be vulnerable to Buffett if, for example, Buffett knows something sensitive about Gates's personal life. But this would not count as an instance of economic vulnerability, for it does not arise systematically from production relations.

19. The form of relational vulnerability I am working with here is therefore individuated independently of sufficiency or decency thresholds (see Section V for related discussion). It follows that superrich capitalists can exploit, indeed dominate, rich capitalists (in Marxist idiom: "big" capital can dominate "medium" capital). It does not follow that the exploitation suffered by workers, or other nonowners of means of production, is not morally more urgent.

20. Such as bodily and mental capacities, including talents. For the significance of this caveat, see G. A. Cohen, Self-Ownership, Freedom, and Equality (Cambridge: Cambridge University Press, 1995), pp. 149-51.

21. Karl Marx, Capital, vol. 1 (New York: Penguin, 1976), p. 799. 
I turn now to my flagship definition of economic exploitation, which is as follows:

(4) A economically exploits B if and only if A and B are embedded in a systematic relationship in which (d) A instrumentalizes B's economic vulnerability (e) to appropriate (the fruits of) B's labor.

(e) needs clarification: A appropriates B's labor when B toils for $\mathrm{H}$ hours, and $\mathrm{A}$ appropriates use-values produced by $\mathrm{B}$ embodying $\mathrm{H}-\mathrm{X}$ hours of toil, for any $\mathrm{H}>\mathrm{X} \geq 0$. A appropriates the fruits of B's labor when $\mathrm{B}$ produces an amount of $\mathrm{H}$ widgets, and $\mathrm{A}$ appropriates $\mathrm{H}-\mathrm{X}$ of these widgets, for any $\mathrm{H}>\mathrm{X} \geq 0 .{ }^{22}$ For simplicity, the discussion proceeds in terms of the fruits of one's labor, which I assume to be an increasing and continuous function of labor time.

Suppose that B produces $\mathrm{H}$ widgets in a rudimentary economy without capital, where $\mathrm{H}$ represents total widget production. Assume, further, that, for whatever reason, $\mathrm{A}$ appropriates $\mathrm{H}-\mathrm{X}, \mathrm{H}>\mathrm{X} \geq 0$. This is an instance of unequal exchange. Unequal exchange obtains just when there is an unreciprocated net transfer of goods or labor time from one party to another. Some philosophers attribute to Marx a "technical" notion of exploitation, according to which unequal exchange is not only a necessary but also a sufficient condition for economic exploitation. It is doubtful that Marx held such a notion. ${ }^{23}$ But whatever Marx thought, the content of the attribution is implausible. For gift-giving implies unequal exchange, but no one thinks (even systematic) gift-giving exploitative. If one part of society freely ${ }^{24}$ decides to pass on a large part of whatever use-values it creates (with its own labor power) to another part of society, the resulting inequality in the consumption of (surplus) labor need not

22. None of what I say implies or requires the labor theory of value, which postulates a correspondence between value and labor time. Moreover, although my definition makes no reference to economic surplus, it is consistent with (indeed, is entailed by) the view that capitalists exploit workers by appropriating surplus labor time. That is, if $\mathrm{N}$ is the net product, $\mathrm{V}$ is the sum of wage goods, and $\mathrm{S}$ is the surplus in a competitive capitalist economy, such that $\mathrm{S}=\mathrm{N}-\mathrm{V}$, then capitalist exploitation normally consists in instrumentalization of the workers' vulnerability to appropriate $\mathrm{S}$.

23. For vindication of these doubts, see Richard Arneson, "What's Wrong with Exploitation?" Ethics 91 (1981): 202-27; Norman Geras, "Bringing Marx to Justice," New Left Review 195 (1992): 37-69.

24. "Freely": not by dint of domination, coercion, or force. 
be objectionable. Only a set of conditions over and above unequal exchange can establish the presence of exploitation. (I claim that the conjunction of [d] and [e] furnishes such a condition.)

III

In this section, I argue that there is a conceptual connection between exploitation and domination. To do this, I first offer a set of sufficient conditions for domination. I then show that the set of necessary and sufficient conditions for exploitation ([d] and [e]) put forward in (4) implies that set of sufficient conditions.

Domination, in its most general form, is subordination offensive to equality of status. More precisely, I take a part of domination to be constituted by disrespectful (that is, degrading, or demeaning, or humiliating) power-overing:

(5) A dominates B if A and B are embedded in a systematic relationship in which (f) A takes advantage of his power over B, or the power of a coalition of agents A belongs to, in a way that is (g) disrespectful to B.

A comment on (f): that A takes advantage of power over B to get B to $\varphi$ (or to $\varphi$ for different reasons) does not imply that A exercises that very power. For B might $\varphi$ strategically, for example, in order to avert exercise of that power. The proverbial playground bully takes advantage of his power to beat up other children when they independently do what he wants them to do without exercising that power.

Two comments on (g): First, any sufficient condition for domination requires something surplus to (f). For, as any parent or lover knows, mere power over another does not suffice for domination. (g) completes the relevant set of sufficient conditions. Second, some action-type, or form of relationship, is disrespectful to $B$ just when it fails to express respect to B. A's $\varphi$-ing, for example, respects B if and only if it expresses a rational (nonpropositional) attitude $\mathrm{R}$ vis-à-vis $\mathrm{B},{ }^{25}$ and $\mathrm{R}$ is dialogically endorsable. One question, then, is which putative attitudes count as dialogically endorsable. Moral philosophers have proposed a number of plausible answers, so I shall simply state the one I believe to be most promising in

25. On rational attitudes, see Elizabeth Anderson, Value in Ethics and Economics (Cambridge, Mass.: Harvard University Press, 1995). 
this context: $\mathrm{R}$ is dialogically endorsable if and only if the considerations giving rise to $\mathrm{R}$ can be advanced as putative justifications for action in the context of embarrassment-free dialogue among interested parties. ${ }^{26}$ "Embarrassment-freeness" obtains when people have no reason to feel shame or guilt for putting or allowing a particular form of justification for some putative act on the table of discourse. An implication of this "expressionist" condition is that the extent to which a particular (set of) interaction(s) between persons embodies respect or recognition depends crucially on their implicit relationship seen in light of a conversation mode, ${ }^{27}$ independently of their actual interactions, prior intentions, and so on.

I shall not dwell further on (5). Suffice it to say that standard instances of domination (the relation between slave and slaveowner, serf and lord, wife and husband in the patriarchal family, and so on) all involve disrespectful power-overing in the broad sense I am interested in here. ${ }^{28}$

I now want to show that (4) implies (5), or, more precisely, that (d) and (e) jointly imply (f) and (g). If I am right, then economic exploitation implies domination. A first step toward this demonstration has already been taken in Section II.A: if (3) is true, then (d) implies (f). That is, when A

26. See G. A. Cohen, Rescuing Justice and Equality (Cambridge, Mass.: Harvard University Press, 2008); Jürgen Habermas, Moral Consciousness and Communicative Action (Cambridge, Mass.: MIT Press, 2001); Philip Pettit, A Theory of Freedom (Oxford: Oxford University Press, 2001).

27. See Stephen Darwall, The Second-Person Standpoint (Cambridge, Mass.: Harvard University Press, 2010); Pettit, A Theory of Freedom.

28. The most advanced students of domination in analytic philosophy are republicans. Republicans define domination as subjection to the arbitrary power of another. See Philip Pettit, Republicanism (Oxford: Oxford University Press, 1997); Quentin Skinner, Liberty before Liberalism (Cambridge: Cambridge University Press, 1998); Lovett, General Theory of Domination. I disagree with those republicans that domination is a form of unfreedom, for domination is consistent with an increase in one's (valuable or valued) options, and therefore consistent with (increased) freedom. (If this were not the case, moreover, there would seem to be no interesting distinction between being dominated and being wrongfully coerced or forced.) But the main reason I do not adopt the republican definition is that I do not know of any sufficiently robust republican account of arbitrariness. Pettit, for example, claims that A has arbitrary power over B if and only if A has power over B and A's (exercise of that) power fails to track B's interests. What these interests are and why failure to track them is a necessary and sufficient condition for domination remain largely unsettled. 
instrumentalizes B's economic vulnerability, he is eo ipso using (or "taking advantage of") his power over B.

\section{$B$}

I must now defend the move from (d) and (e) to (g), that is:

(6) If A instrumentalizes B's economic vulnerability to enrich himself, then A affects B in a way that is disrespectful to B.

Note, first, that the appropriation of the fruits of another's labor is a form of self-enrichment, for it confers on the appropriator a net material gain: A enriches himself in that minimal sense. ${ }^{29}$ Exploitation thus consists in someone's enrichment from the instrumentalization of another's vulnerability. ${ }^{30}$

Now, (6) is not unlike most substantive moral claims, in that it is not directly amenable to proof. All one can do is propose intuition-eliciting examples and show why these intuitions withstand the test of counterexample in reflective equilibrium with other judgments and theories. I claim that paradigmatic instances of exploitation, such as those represented in Zola's Germinal, Dickens's Oliver Twist, Lars Von Trier's Dogville, and David Lynch's Elephant Man, all share this property of vulnerability-instrumentalization. And I also claim that the reason we are appalled by the content of these relationships is precisely that they are humiliating, demeaning, or degrading (in a word: disrespectful) to the underdog, whose vulnerabilities are treated as opportunities for selfenrichment. ${ }^{31}$ As I shall argue in Sections V and VI, alternative explanations for our disapproval of these relationships do not withstand scrutiny at reflective equilibrium.

29. Of course, such appropriation need not involve enrichment only for A: B might also gain from the transaction.

30. One can instrumentalize another's vulnerability not, strictly, to enrich himself but, more broadly, to serve his own interests. A's interests are served when A instrumentalizes B's vulnerability to get B to $\phi$, both where $\phi$-ing improves A's position and where B's $\phi$-ing leaves A as well off as he would otherwise have been (assuming A is sufficiently well off). These two notions of "serving one's interests" correspond to what may be called selfenriching and conservative vulnerability-instrumentalization, respectively. Exploitation by definition rules out conservative vulnerability-instrumentalization.

31. It does not follow that exploitation is wrongful domination-independently. Our rational disapproval vis-à-vis exploitative practices is conceptually entangled with our disapproval vis-à-vis a particular form of power-over, namely, domination. 
If (3) and (6) are true, then (d) and (e) suffice for (f) and for (g). ${ }^{32}$ It follows that (4) implies (5), that is, A's instrumentalization of B's economic vulnerability for A's enrichment is a form of domination. ${ }^{33}$ This concludes my positive argument, which I must now summarize.

A economically exploits B.

$\therefore \quad$ A instrumentalizes B's economic vulnerability to appropriate B's labor. (from [4])

$\therefore \quad$ A instrumentalizes B's economic vulnerability to enrich himself. (from the fact that labor-appropriation enriches)

$\therefore \quad$ A takes advantage of his power over B in a way that is disrespectful to B. (from [3], [6])

$\therefore \quad$ A dominates B. (from [5] $)^{34}$

32. Which further implies that they suffice for (f) and (g), since if $d \& e \rightarrow f$ and $d \& e \rightarrow$ $g$, then $d \& e \rightarrow f \& g$.

33. Several authors have noticed that exploitation implies power-over. Wolff identifies "exploiting someone's circumstances" with "exploiting the power one has over another" and notes that "the notion of having exploitable circumstances seems equivalent to that of being vulnerable." Both are, he says, necessary for exploitation. Jonathan Wolff, "Marx and Exploitation," Journal of Ethics 3 (1998): 105-20, at p. 111. Goodin similarly claims that exploitation is a kind of "abuse of power." Goodin, "Exploiting a Person," p. 184. Neither of these authors claims there is a necessary connection between exploitation and domination. Indeed, Goodin explicitly locates the wrongmaking feature of exploitation not in the nature of the form of power-over that the actualization of exploitation implies, but rather in the violation of a duty to protect the vulnerable. But one can protect and exploit, indeed, protect the vulnerable by exploiting them. Suppose A is after B, and will kill B if he gets him. I can protect B (only) by hiring him in my factory for a sweatshop contract. In these circumstances I would be protecting B by exploiting him. Note that this possibility is not mere high-flown fancy: the quintessentially capitalist institution of the labor market systematically enforces a social distinction between exclusion from and inclusion into work. Even where exclusion does not imply starvation (the "kill" option), the principal means capitalism mobilizes for protecting the vulnerable is the commodification of their labor power through inclusion in the labor market (the "exploit" option).

34. Roberto Veneziani points out (in private communication) that if exploitation is the unfair taking of advantage (à la Wertheimer) and if disrespect is a special case of unfairness, then domination could be a special case of exploitation, and not vice versa. Alan Wertheimer and Matt Zwolinski, "Exploitation," Stanford Encyclopedia of Philosophy, Spring 2013 ed., ed. Edward N. Zalta, <http://plato.stanford.edu/archives/spr2013/entries/ exploitation/>. I argue against the first premise of this argument in Section VI. I discuss the second premise in a postscript to this article entitled "Why Marxists Should Be Interested in Exploitation," which is available from me upon request. 
I have so far argued that there is a conceptual connection between economic exploitation, on the one hand, and domination, on the other:

(7) If A economically exploits B, then A dominates B.

I now face a preliminary objection. The putative objector sets out from an implication of (7), to the effect that individual capitalists dominate individual workers. But this, the objector says, is implausible: even if capitalist A exploits his worker B, he does not eo ipso dominate B. ${ }^{35}$ So (7) is false. Now consider:

Three Thugs: A man, $B$, is threatened by a gang of three thugs, $A_{1}, A_{2}$, and $A_{3}$. The thugs are weak, such that none of them could take $B$ down individually. But all three could: their being (at least) three is a necessary and sufficient condition for taking B down. Assume this is common knowledge. By threatening to take $B$ down if he does not hand over his money, $A_{1}$ gets $B$ to give him the money. $A_{1}$ runs away, never to share the loot with $A_{2}$ and $A_{3}$.

In Three Thugs it is true of each $\mathrm{A}_{\mathrm{i}}, \mathrm{i} \in\{1,2,3\}$ that he dominates $\mathrm{B}$. But a necessary condition for him dominating is that the others be present and, if instructed, take $B$ down. Thus, $A_{i}$ can dominate $B$ even if $A_{i}$ cannot individually get $\mathrm{B}$ to do what he would not otherwise have done. It is therefore not incoherent to maintain, by analogy, that individual capitalists dominate individual workers, even when individual capitalists cannot dominate individual workers individually. Indeed, the example seems to vindicate the common-stock socialist idea that the capitalist class dominates the working class, and it is in virtue of such collective domination that individual domination and indeed exploitation are possible.

Let $P a_{N} b$ be the power possessed by $A_{N}$, the thugs taken as a coalition, that is, their collective ability to get $B$ to do things. When thug $A_{i}$ gets $B$ to

35. Indeed, denying this seems to contradict a revered Marxian canon, according to which the individual worker is "property, as it were, of the entire bourgeois class" and not of any individual capitalists. Frederick Engels, The Principles of Communism, in MarxEngels Selected Works, vol. 1 (Moscow: Progress Publishers, 1969); Karl Marx, Wage-Labour and Capital (New York: International Publishers, 2006), p. 20. 
hand over his money, he is taking advantage of that very power, $P a_{N} b$, and it is in this sense that $A_{i}$ dominates $B$. In the capitalist-worker case, the structure is exactly thug-like: $A_{i}$ takes advantage, not (necessarily) of $P a_{i} b$, but of $P a_{N} b$, that is, the collective ability of coalition $A_{N}$ (to which $A_{i}$ belongs) to get $B$ to produce a surplus destined for appropriation by some capitalist. ${ }^{36}$ (A sufficient condition for $P a_{N} b$ to apply is the presence of some form of collective or "conjunctive" vulnerability of the sort discussed by Goodin.) ${ }^{37}$ This is how capitalist $A_{i}$ dominates B.

Under realistic assumptions, therefore, when $A_{i}$ economically exploits $B, A_{i}$ dominates $B,{ }^{38}$ and the preliminary objection to (7) fails. My rebuttal to this objection shows why the notion of class may have an important and subtle role to play on any domination-based account of exploitation. I now turn to alternative accounts of exploitation. My purpose is to show that the domination-based account is superior.

V

Perhaps the most influential-and certainly the most analytically sophisticated-contemporary theory of economic exploitation is due to John Roemer. In a series of innovative articles, Roemer has argued against traditional Marxist accounts of exploitation and proved a series of correspondence theorems pertaining to exploitation and asset inequality, exploitation and class location, and so on. I shall focus on Roemer's account of capitalist exploitation.

36. There seems to be a disanalogy between the typical form of interaction between capitalist and worker and that between thug and thug-victim. For thug $\mathrm{A}_{\mathrm{i}}$ cannot get $\mathrm{B}$ to hand over the loot to him individually, but can get him to do so collectively, that is, in the company of $A_{j}, j \neq i$. Yet capitalist $A_{i}$ can do neither: he cannot get $B$ to work for him, whether collectively or individually. Someone might thus infer that $A_{i}$ cannot possibly be dominating $\mathrm{B}$. The inference would be invalid. For it is true of each thug $\mathrm{A}_{\mathrm{i}}$ that he dominates $B$ even if it is not true of each $A_{i}$ that he is capable of getting $B$ to hand over the loot to him (for example, because the others would prevent such a transfer, or because he cannot handle loot, or because he is an idiot). There is, therefore, no relevant disanalogy between individual thug and individual capitalist. I am grateful to an anonymous referee for insisting on this issue.

37. Goodin, Protecting the Vulnerable, p. 136.

38. The set of assumptions for successful class domination must include the following: no candidate dominator can dominate individually; candidate dominators have common interests; and they dispose of mechanisms to enforce such interests through the prevention or deterrence of free riding. (One such coordination mechanism under capitalism is naturally the state.) For discussion, see Jon Elster, Making Sense of Marx (Cambridge: Cambridge University Press, 1983), chap. 7. 
According to an influential (pre-Roemerian) Marxist account:

(8) A exploits B if and only if A extracts forced, unpaid, surplus labor from B. ${ }^{39}$

This definition has the exegetical advantage that it accords with much of what Marx says about worker "compulsion" under capitalism, and suggests a rough-and-ready set of necessary and sufficient conditions for economic exploitation. It is the forced nature ${ }^{40}$ of the labor flow between capitalists and workers that makes or breaks the case for (capitalist) exploitation.

But (8) is (exegetically and) ${ }^{41}$ definitionally inadequate. Here is an argument as to why forced transfer (of unpaid surplus labor) furnishes no sufficient condition for exploitation. Societies with welfare states generally provide for the sick and disabled, among others. Those welfare beneficiaries receive a net transfer of labor time from able-bodied taxpayers. The able-bodied are, moreover, forced, because coerced by the state, to engage in these net transfers. But no one wants to say that the disabled or the sick exploit the able-bodied. ${ }^{42}$

What about forced transfer as (part of) a necessary condition for exploitation? Consider a variation on an example due to Roemer: ${ }^{43}$

Two Plots: A and B own different plots of land, A's more productive than B's, and have identical cardinal utility functions of the form $u=a x$, where $x$ is the amount of widgets consumed. If they do nothing, then their land will magically generate $\bar{x}$ for each, such that they both enjoy a perfectly decent level of utility $a \bar{x}$. A offers B work on A's land, which is much more productive than B's when worked on by

39. For well-known defenses of (8), see Nancy Holmstrom, "Exploitation," Canadian Journal of Philosophy 7 (1977): 353-69; R. G. Peffer, Marxism, Morality and Social Justice (Princeton, N.J.: Princeton University Press, 1990); Jeffrey Reiman, "Exploitation, Force, and the Moral Assessment of Capitalism," Philosophy \& Public Affairs 16 (1987): 3-41.

40. A is forced to $\phi$ if and only if A has no reasonable or acceptable alternative to $\phi$-ing.

41. Exploitation as domination for self-enrichment does a better job exegetically, or so I argue in "Why Marxists Should Be Interested in Exploitation."

42. And Marx certainly does not. See, e.g., Karl Marx, "Critique of the Gotha Programme," in Selected Works in One Volume, by Marx and Engels (London: Lawrence and Wishart, 1968), chap. 1. Note that the truth of "A exploits B" does not imply that A himself disposes of the means to exploit B (for example, a monopoly over the legitimate use of violence).

43. John Roemer, Egalitarian Perspectives (Cambridge: Cambridge University Press, 1996). 
human hands. If B accepts A's offer, he will produce $N$ widgets and consume $\hat{x}$, where $\hat{x}>\bar{x}$ ( $\hat{x}$ is also sufficiently large to compensate for the disutility of labor, if any). A will then consume $N-\hat{x}$, where $N-\hat{x}>>\hat{x}$, without working at all. B accepts the offer.

Roemer argues, plausibly, that this sort of interaction is exploitative. But B is forced neither by his economic circumstances nor by third parties to enter into it. Hence, force does not furnish a necessary condition for exploitation.

The scenario just envisaged raises the further, interesting question of whether there can be exploitation in a world with a substantial unconditional basic income (UBI). I think Two Plots can be amended to show that this is perfectly possible. Consider:

Basic Income: Same ownership and preference structure as above. The main difference lies in A's offer to B: A will work for a total of two hours on his own land and produce $\bar{x}$, to be passed on to B for consumption. $B$, on the other hand, will work for twelve hours on A's land and produce $N$, of which he will keep an amount $\varepsilon$. B's final consumption will be $\hat{x}=\bar{x}+\varepsilon$ ( $\hat{x}$ is also sufficiently large to compensate for the disutility of labor, if any). A's final consumption will be $N-\varepsilon>>\hat{x}$. $B$ accepts the offer.

As before, A's superior cut in the means of production allows him to consume much more labor than he expends by appropriating B's surplus product (here $N-\varepsilon$ ). If Two Plots is exploitative, then Basic Income is exploitative. Furthermore, B's position in this example seems exactly analogous to that of the UBI beneficiary receiving $\bar{x}$ under conditions of advanced capitalism. ${ }^{44}$ Hence, basic income capitalism can be exploitative. ${ }^{45}$

44. For an argument that UBI and advanced capitalism are compossible, see Philippe Van Parijs, Marxism Recycled (Cambridge: Cambridge University Press, 1993), part 4.

45. If I am right, then UBI is, at best, only a necessary condition for human emancipation. Opponents of UBI object that it is not even that. Their argument tends to go roughly as follows: Under UBI, nonworkers appropriate the fruit of workers' labor. All such appropriation is exploitative. Therefore UBI is exploitative. See, e.g., Gijs Van Donselaar, The Right to Exploit (Oxford: Oxford University Press, 2008). As it stands, this argument is untenable. For its major premise implies, implausibly, that sick and disabled nonworkers who benefit from a UBI (or any redistribution, for that matter) exploit workers. The premise can, of course, be amended to apply only to the able-bodied. (This restriction would raise 
In light of all this, Roemer argues that what is wrong with examples like Two Plots is injustice in the distribution of alienable assets. Thus, for any coalition of agents A and its complement B, Roemer claims:

(9) A exploits B if and only if:

(i) were B to withdraw from the society, endowed with its per capita share of society's alienable property (that is, produced and nonproduced goods) and with its own labor and skills, then B would be better off (in terms of income and leisure) than it is at the present allocation;

(ii) were A to withdraw under the same conditions, then $\mathrm{A}$ would be worse off (in terms of income and leisure) than it is at present;

(iii) were B to withdraw from society with its own endowments (not its per capita share), then A would be worse off than at present. ${ }^{46}$

In this connection, Roemer has argued that exploitation itself is, at best, a morally secondary phenomenon (if morally significant at all) ${ }^{47}$ According to Roemer, the locus of our normative interest should be the (in)justice of property relations. ${ }^{48}$

I now want to argue that the Cohen/Roemer account fails to supply a necessary condition for exploitation, whether or not it furnishes a sufficient condition. Roemer attacks the notion of exploitation as unequal exchange in "Should Marxists Be Interested in Exploitation?" He returns a negative answer to that question:

the question of how, if at all, the revised major premise can be defended in a principled way, given that its main source of support is some reciprocity requirement.) Even if such a restricted version of the argument can form the proper basis for a theory of exploitation (which there is reason to doubt), the positive account defended here can afford to remain agnostic about its merits. I thank an anonymous referee from bringing this argument to my attention.

46. Roemer, Egalitarian Perspectives, p. 40.

47. Ibid.; John Roemer, "Should Marxists Be Interested in Exploitation?" Philosophy \& Public Affairs 14 (1985): 30-65.

48. See also G. A. Cohen, "The Labour Theory of Value and the Concept of Exploitation," Philosophy \& Public Affairs 8 (1979): 338-60. 
for the sake of clarity and consistency, I think exploitation conceived of as the unequal exchange of labour should be replaced with exploitation conceived of as the distributional consequences of an unjust inequality in the distribution of productive assets and resources. ${ }^{49}$

What constitutes unjust inequality? Roemer affirms a theory of equality of opportunity that has come to be called "luck egalitarianism": the distribution of $\mathrm{x}$ (where $\mathrm{x}$ is some desideratum of justice) between $\mathrm{A}$ and $B$ is just if and only if any difference between A's and B's enjoyment of $x$ reflects a difference in their choices, deserts, or faults. Any inequality that violates this principle implies involuntary disadvantage: ${ }^{50}$

(10) A exploits B if and only if the exchange in which they are engaged occurs against the background of an unjust distribution, that is, a distribution involving involuntary disadvantage. ${ }^{51}$

Assuming individual choices reflect (unmanipulated) preferences, a corollary of (10) is that:

(11) Any distribution that reflects nothing but differences in (unmanipulated) preferences is just, and therefore not exploitative.

The rest of this section proceeds by arguing that (10) and its corollary should be rejected. ${ }^{52}$

A

Consider:

Rescuer: A finds B in a pit. A can get B out at little cost or difficulty. A offers to get $B$ out, but only if $B$ agrees to pay a million euros or to sign a sweatshop contract with A. B signs the contract.

49. Roemer, Egalitarian Perspectives, p. 96.

50. See ibid., pp. 179-98; G. A. Cohen, "On the Currency of Egalitarian Justice," Ethics 99 (1989): 906-44. Roemer does not formulate his own view in terms of involuntary disadvantage (as opposed to "equal shares"), but this terminological difference is insubstantial.

51. (9) follows from (10) if any lack in one's per capita share constitutes involuntary disadvantage.

52. Section VI.A draws upon Nicholas Vrousalis, "G. A. Cohen on Exploitation," Politics, Philosophy and Economics (2013). 
This exchange is paradigmatic of exploitation: if this is not an instance of exploitation, then nothing is. Yet thinking that B's acceptance of the offer results in A exploiting B is inconsistent with (10). For A's offer can be forthcoming even in the absence of involuntary disadvantage, or indeed any sort of distributive injustice: B may have found himself there through just steps, from a just starting position. B may, for example, have chosen not to purchase cheap insurance against falling in pits or against being rescued afterward. Alternatively, the pit may be the bottom of a huge vanilla ice cream cone, and B may have ended up there by intentionally licking all of the ice cream. It does not follow, and it is false, that the offer is not exploitative: A can rescue B without asking for anything, but instead uses B's vulnerability in order to improve his own lot. ${ }^{53}$ It follows that asset injustice furnishes no necessary condition for exploitation, and therefore no proper basis for a charge of exploitation. ${ }^{54}$

\section{$B$}

By way of illustration of this rather general complaint against (10), I must now rehearse the possibility of a "cleanly generated capitalism," a form of capitalism that does not arise from "primitive accumulation," through massacre, plunder, forced extraction, or, quite generally, through transgression of some norm of distributive justice. Rather, it arises from "clean" social interactions: a laborer, or a class of laborers, manages to accumulate significant quantities of capital through toil and savings, thereby turning himself into a capitalist. ${ }^{55}$

Consider a limiting case of cleanly generated capitalism:

53. Someone might object that A's offer is exploitative because it is coercive. But, as I argued in Section $\mathrm{V}$, force and coercion are neither necessary nor sufficient for exploitation. The wrongmaking features of Rescuer must be sought neither in coercion, nor in force, nor, as I argue presently, in distributive injustice.

54. More generally, this triad is inconsistent: (i) exploitation is unfair advantage-taking, (ii) unfairness is responsibility-constrained equality, (iii) exploitation can arise from any material inequality. (ii) and (iii) are very compelling. I claim that (i) must be rejected. On my view, exploitation is not tantamount to unfair advantage-taking, for there can be fair exploitings.

55. Marx himself envisages a similar possibility, arising from the laborer's "own labour and that of his forefathers," in Marx, Capital, p. 728. On Marx's account he still exploits the worker. 
Ant and Grasshopper: Grasshopper spends the summer months singing, whereas Ant spends all his time working. When the winter comes, Grasshopper needs shelter, which he presently lacks. Ant has three options: he can do nothing to help Grasshopper, he can offer him shelter that costs Ant nothing, or he can offer him costless shelter on the condition that he signs a sweatshop contract. The possibilities, in the relevant metric, are:

(Ant, Grasshopper)

(i): Do nothing: $(10,1)$

(ii): Sweatshop: $(12,2)$

(iii): Shelter: $(10,3)$

Now, it is plausible to think that Ant has an obligation to help Grasshopper. But one need not have a view on that to believe that (ii) is morally worse than (iii). That is, if Ant decides to help (decides to do something other than [i]), then he must not opt for (ii), in part because doing so constitutes exploitation. I take the widely shared intuition expressed in this consequent as evidence that the vulnerability-based definition of exploitation is plausible. But now note that if (ii) involves exploitation, then asset injustice furnishes no necessary condition for it. For, according to (10), all of (i), (ii), and (iii) are equally acceptable at the bar of asset justice.$^{56}$ Roemer and other Marxist advocates of (10) have nothing to oppose to such a cleanly generated capitalism on exploitation grounds, and this is an embarrassment to their claims to holding a socialist, or a socialism-friendly, theory of equality. This result generalizes, I believe, to any theory of exploitation that posits some defensible account of asset injustice as a necessary condition for exploitation. ${ }^{57}$

56. (ii) is, after all, an upshot of Grasshopper's own choices or faults. One can construct examples where the demands of distributive justice are not only unnecessary for but also contradict (what are intuitively) claims of exploitation. See Vrousalis, "G. A. Cohen on Exploitation."

57. Take another prominent example: leximin. Leximin does indeed dub (iii) as the most just distribution of widgets, and therefore seems to give the intuitive answer. But the result is misleading. Assume the shelter outcome turns out to provide no substantial improvement in Grasshopper's condition, as follows:

(Ant, Grasshopper)

(i): Do nothing: $(10,1)$

(ii): Sweatshop: $(12,2)$

(iii*): Shelter: $(10,2)$ 
The reason why exploitation survives in the absence of distributive injustice, I submit, is that exploitation constitutes procedural injury to status, and status-injury is not reducible to distributive injury. ${ }^{58}$

In this section, I have argued that judging (ii) as wrongfully exploitative supports (4) and undermines (10). If I am right, and if (4) has the conceptual connection with (5) that I have claimed, then exploitation is best viewed as a form of domination. On the view defended here, domination is the distinct vice that sits in the (hitherto largely unexplored) conceptual realm between coercion and unfairness. But now I face another objection, articulated by Roemer himself, to the effect that exploitation is broader in scope than domination and cannot, therefore, be a form of domination. I turn to this objection presently.

VII

In his early work, Roemer affirms a variation on (9), in which (iii), the "withdrawal with one's own share" condition, is replaced by "A being in a relation of dominance to B." ${ }^{59}$ The reason some such condition is conceptually indispensable is that (i) and (ii) do not jointly suffice for exploitation. If they did, then two individuals who never interact with each other but control unequal amounts of assets could exploit one another ${ }^{60}$

Roemer's dominance condition fills this gap by making the exploiter's well-being dependent on (the nature of the) interaction with the exploitee. In his later work, Roemer offers some hints as to why he came to reject this earlier emphasis on domination:

In this case, leximin dubs (ii) as the most just distribution, and therefore produces a counterintuitive result (and so does maximin, which recommends choosing between [ii] and [iii*] on a coin toss). Exploitation and distributive injustice again part ways.

58. For some discussion of the former claim, see Stuart White, "The Citizen's Stake and Paternalism," Politics and Society 32 (2004): 61-78; for a defense of the latter claim, see Elizabeth Anderson, "What's the Point of Equality?" Ethics 109 (1999): 287-337. Status equality (causally) requires some measure of equality in distribution, and may sometimes mandate compensation for involuntary or brute luck disadvantage. But then again it may not.

59. John Roemer, A General Theory of Exploitation and Class (Cambridge: Cambridge University Press, 1982), p. 195.

6o. For an early critique of the early Roemerian definition, see Christopher Bertram, “A Critique of John Roemer's General Theory of Exploitation," Political Studies 36 (1988): 123-30. 
It is necessary to distinguish two types of domination by capitalists over workers, domination in the maintenance and enforcement of private property in the means of production, and domination at the point of production (the hierarchical and autocratic structure of work). The line between the two cannot be sharply drawn, but let us superscript the two types domination ${ }_{1}$ and domination $\mathrm{n}_{2}$, respectively.

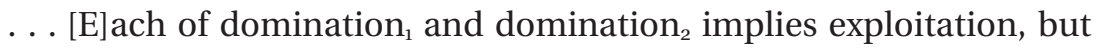
not conversely. Hence if our interest is in domination, there is no reason to invoke exploitation theory, for the direction of entailment runs the wrong way. . . . In certain situations, exploitation requires domination $_{1}$, but since we cannot know these cases by analyzing the exploitation accounts alone, there is no reason to invoke exploitation if, indeed, our interest in exploitation is only as a barometer of domi-

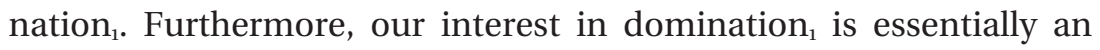
interest in the inequality of ownership of the means of production, for the purpose of domination ${ }_{1}$ is to enforce that ownership pattern. I maintain if it is domination ${ }_{1}$ one claims an interest in, it is really inequality (however defined) in the ownership of the means of production which is the issue. ${ }^{61}$

Given the significance of this objection to the overall integrity of my thesis, I propose to study it at some length. I proceed as follows: First, I reconstruct Roemer's account of domination ${ }_{1}$ and domination ${ }_{2}$. I then rebut his antidomination conclusion on the grounds that the forms of domination he discusses do not exhaust the sphere of domination tout court. Exploitation is simply a "third form" of domination, equivalent to neither domination nor domination $_{2}$. In the course of this rebuttal, several points of agreement with Roemer will surface.

A

Here is a reconstruction of Roemer's argument against the view that exploitation implies domination :

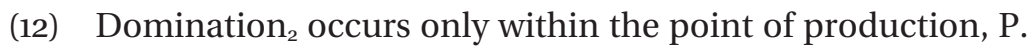

(13) Exploitation does not occur only within P.

$\therefore(14)$ Some instances of exploitation are not instances of domination . $_{\text {. }}$

61. Roemer, Egalitarian Perspectives, p. 73. 
$\therefore$ (15) Our interest in domination ${ }_{2}$ cannot justify an interest in exploitation. ${ }^{62}$

Roemer defines domination ${ }_{2}$ in terms of the "hierarchical and autocratic structure of work": (12) follows from this definition. (13) is trickier to defend. Unlike most Marxists before him, Roemer claims that A can exploit B even in the absence of labor or credit markets.$^{63}$ Here is a brilliant illustration of that claim:

Friday and Robinson: There are two producers, Friday and Robinson. Friday is capital-poor, and Robinson is capital-rich. If they do not trade, Robinson will work eight hours and Friday will work sixteen so that each can satisfy his needs. (Assuming they are both rational, the fact that they decide to trade shows that they both benefit from trading.) They only trade in final goods, and there are no labor or credit markets. In equilibrium under free trade, Friday works twelve hours, Robinson works four, and both attain subsistence. ${ }^{64}$

Roemer claims there is exploitation here. Having worked for four hours, Robinson can relax for the rest of the day, while Friday toils to produce what Robinson would otherwise have produced only with an extra four hours of work:

Robinson benefits from Friday's presence, and is able to use his wealth as leverage, through the market, to get Friday to work for him, which Friday would not have to do if he had access to his per capita share of the produced capital..$^{65}$

I agree with Roemer's conclusion, and I also agree that it vindicates

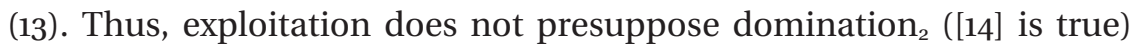
and an interest in domination ${ }_{2}$ cannot justify an interest in exploitation ([15] is true).

62. Ibid., p. 77 .

63. See Roemer, General Theory of Exploitation.

64. Roemer, Egalitarian Perspectives, pp. 52-53.

65. Ibid., p. 52. 
$B$

I now proceed to Roemer's more general argument against the view that exploitation and domination are related in the way advocated in (7):

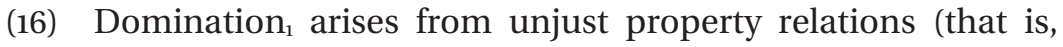
asset injustice).

(17) Exploitation is only a "barometer" for domination . $_{1}$

$\therefore$ (18) We should be interested in domination ${ }_{1}$, not exploitation.

(16) is true by definition. (17) says that exploitation provides an indication or prediction of domination ${ }_{1}$, just as barometers indicate or predict the weather. ${ }^{66}$ And since we are only interested in predictions because we are interested in the weather, it follows, by analogy, that exploitation is of no intrinsic interest, which is what (18) says. Adding the premise:

(19) Domination and domination $_{2}$ are the only forms of domination tout court.

It follows that:

(20) An interest in domination tout court cannot justify an interest in exploitation. (from [15], [18], and [19])

Whatever one thinks about the inference to (18), the inference to (20) seals off any appeal to domination as explanans of our interest in exploitation and concludes Roemer's attack on that front.

C

My response to Roemer consists in showing that his account of domination is too narrow, that is, consists in refuting (19). For it is plausible, I think, that there exist instances of domination (i) that do not arise from asset injustice (that is, are not instances of domination $_{1}$ ), and (ii) that do not take place at the point of production (that is, are not instances of domination ${ }_{2}$ ).

I begin by defending claim (ii). Roemer's own Friday and Robinson example is purported to show that exploitation can take place outside the point of production. But why is the same not true of domination? Roemer says that Robinson "is able to use his wealth as leverage to get

66. Ibid., p. 73 . 
Friday to work for him," adding that this is something "Friday would not have to do if he had access to his per capita share of the produced capital" (emphases mine). It follows that Robinson can instrumentalize Friday's vulnerability to get Friday to do something he would not otherwise have done (or would not have done for the same reasons) in order to obtain a material gain. As I argued in Section III, there is nothing counterintuitive about saying that such instrumentalization is tantamount to domination.

One reason why Roemer wants to resist the domination-based description seems to be that he takes domination to be coextensive with the absence of perfect competition:

where markets for particular assets or commodities are thin ... one agent has power over another which he would not have in a fully developed, perfectly competitive market economy. ${ }^{67}$

Now, given domination implies power over, it follows by modus tollens that "fully developed" perfect competition excludes the possibility of domination. Yet Roemer (and indeed Marx) thinks that exploitation supervenes even in a perfectly competitive capitalist economy (which I take to be a system of generalized commodity production in which there are no externalities and in which all producers face infinitely elastic demand schedules, that is, have no market power). Therefore not all instances of exploitation are instances of domination. In response to this line of argument, it bears repeating that even under "fully developed" perfect competition, a class of people (owners of the means of production) can "get" others (nonowners) to do things those others would not otherwise have done by instrumentalizing their vulnerability (that is, their nonownership of such means) in order to make money. All these are instances of power-over and, indeed, instances of domination (as betrayed by Roemer's own language). The first premise of Roemer's argument, that domination is coextensive only with the absence of perfect competition, is therefore false. ${ }^{68}$

I now turn to (i), the view that domination always arises from asset injustice. Consider:

67. Ibid., p. 74 .

68. I am here also opposed to Lovett, General Theory of Domination, p. 79. 
Slavery Contract: A and B are identical twins starting from exactly equal bargaining positions. Each freely agrees to the following contract: on a 50/50 coin toss, the one who gets heads enslaves himself for life to the one who gets tails. B gets heads. ${ }^{69}$

In this example, domination arises from conditions of full asset justice through the voluntary, unmanipulated choices of free agents. The example shows why complaints of (Roemerian) asset injustice are unnecessary for a charge of domination (and therefore why [i] is false).

I tentatively conclude that it is not implausible to think that there are forms of domination that correspond neither to domination (asset injustice) nor to domination ${ }_{2}$ (point-of-production autocracy). If such a "third form" of domination exists, then (20) fails to follow. The thesis that an interest in exploitation can be justified by an interest in domination has not been refuted by Roemer.

VIII

Let us take stock. I began by defining economic exploitation as the instrumentalization of someone's economic vulnerability for the appropriation of (the fruits of) his labor. Under capitalism, economic vulnerability is determined by relations of effective control over labor power and the means of production. Such relations permit capitalists (owners of the means of production) to instrumentalize the vulnerability of workers (nonowners of such means) to appropriate the surplus the latter produce. I then argued that exploitation implies domination of workers by capitalists, and defended the view that domination is distinct from and not reducible to distributive injustice. I also implied that class domination cannot be abolished without abolishing capitalist relations of production. Such abolition is not, moreover, normally sufficient for the removal of class domination. Differences in talents and knowledge can generate domination, thus paving the way for "postindustrial" forms of economic exploitation. ${ }^{70}$ Under technocracies, economic vulnerability

69. See Cohen, Self-Ownership, Freedom, and Equality, p. 47.

70. In Roemer's schema, means-of-production equality abolishes "capitalist" exploitation, but not "socialist" exploitation, that is, unjust flow generated by differences in status, knowledge, or talent. Roemer, General Theory of Exploitation. Nonexploitative societies transcend both "capitalist" and "socialist" forms of exploitation. See also Erik Olin Wright, Classes (London: Verso, 1985). 
is determined by relations of effective control over knowledge and technical expertise. Such control permits technocrats (owners of knowledge assets) $^{71}$ to instrumentalize the vulnerability of nontechnocrats (nonowners of such assets) to appropriate the surplus the latter produce. ${ }^{72}$

This article has largely focused on distribution and class domination. For all I have shown, however, it is still possible that class division under capitalism is but the expression of a deeper form of social domination immanent to this social system: that of "dead" over "living" labor, or of capital over human beings. If there is a nontrivial, ontologically nonsuspicious sense in which this is right, then capitalist domination can conceivably survive the removal of capitalists (a possibility crisply encapsulated in the much-vaunted oxymoron of "market socialism"). A satisfactory critique of capitalism would, I think, need to study the antecedent and the consequent of this conditional by drawing upon the rich traditions of both critical theory and analytic political philosophy. ${ }^{73}$

71. In Classes, Wright uses the (broader) term "organization assets."

72. I discuss technocracy and some of the implications of the account defended here for socialism in "Why Marxists Should Be Interested in Exploitation."

73. For rudiments toward such a critique in the former tradition, see Moishe Postone, Time, Labor, and Social Domination (Cambridge: Cambridge University Press, 1993). 